\title{
REALIDADES DE LA POLÍTICA PÚBLICA PARA LAS VÍCTIMAS DESDE LAS NARRATIVAS DE MUJERES NEGRAS DESPLAZADAS POR EL CONFLICTO ARMADO INTERNO EN COLOMBIA*
}

\author{
Jorge Eduardo Vásquez Santamaría** \\ Bibiana Escobar García* \\ Recibido: Noviembre 19 de 2013 \\ Aprobado: Febrero 20 de 2014
}

\begin{abstract}
RESUMEN
Desde la identificación, descripción y análisis de los referentes que dan lugar a la política pública que viene siendo consolidada para atender a los afrocolombianos víctimas del conflicto armado interno en Colombia, se devela un énfasis reduccionista en figuras jurídicas y algunas medidas dispuestas para el amparo de los derechos humanos. Estos referentes son contrastados con las narrativas de las mujeres negras desplazadas por el conflicto, develando evidencias de sus vivencias y los efectos generados en lo público y lo privado, desprendiendo de ello reorientaciones a los referentes que se vienen empleando en la elaboración de la política pública para víctimas con un enfoque étnico.
\end{abstract}

Palabras claves: mujer, negra, desplazada, conflicto, política pública.

* Producto final de la investigación "Mujer, Negra, Desplazada: Memorias de un pueblo negro", financiado por el Ajuntament de Barcelona, y la Asamblea de Cooperación por la Paz, de España, la Fundación Forjando Futuros, y la Universidad Autónoma Latinoamericana de Medellín, Colombia. Los autores participaron como investigadores de la Facultad de Derecho de la Universidad Autónoma Latinoamericana en la línea de investigación "Cultura Latinoamericana, Estado y Derecho". Participaron como coinvestigadores Nora Isabel Saldarriaga Flórez, Beatriz Villegas Sierra, Walter Raúl Mejía Cardona y Alexander Nizhelski Álvarez de la Fundación Forjando Futuros, y como auxiliares de investigación de la Facultad de Derecho de la Universidad Autónoma Latinoamericana, las estudiantes Olga Beatriz Vallejo Blandón y Nora Viviana Echavarría Cano.

** Abogado y candidato a Magister en Derecho de la Universidad de Medellín. Especialista en Docencia Investigativa Universitaria de la Funlam. Docente Investigador del Grupo de Investigaciones Ratio Juris. Facultad de Derecho Universidad Autónoma Latinoamericana.jorge.vasquez@unaula.edu.co

*** Licenciada en Educación, Historia y Filosofía de la Universidad Autónoma Latinoamericana. Magister en Educación de la Universidad de Manizales; candidata a Doctorado en Filosofía Universidad Pontificia Bolivariana. Docente de la Facultad de Derecho de la Universidad de San Buenaventura de Medellín. bescobarg@gmail.com 


\title{
REALITIES OF PUBLIC POLICY ON VICTIMS BASED ON STORIES OF BLACK WOMEN DISPLACED BY THE COLOMBIAN ARMED CONFLICT
}

\begin{abstract}
As far as legal institutions and measures for protecting human rights are concerned, it is perceived a reduccionist emphasis within public policy references on Afrocolombian victims of domestic armed conflict. These versions are confronted with stories furnished by black women displaced by conflict, that reveal their experiences and their effects in public and prívate sectors. The black women's discourse reorient the realities that are taken into account in order to make public policy on victims with an ethnical approach.
\end{abstract}

Key words: Black woman, displaced, conflict, public policy.

\section{REALIDADES DA POLÍTICA PÚBLICA PARA AS VÍTIMAS DE MULHERES PRETAS NARRATIVAS DESLOCADAS PELO CONFLITO ARMADO INTERNO NA COLÔMBIA}

\section{RESUMO}

Desde a identificação, descrição e análise das referências que dão origem a política pública que foi criada para atender a afro vítimas do conflito armado interno na Colômbia, revela uma ênfase reducionista sobre conceitos jurídicos e algumas medidas previstas proteção dos direitos humanos. Essas referências são contrastadas com narrativas de mulheres negras deslocadas pelo conflito, revelando evidências de suas experiências e os efeitos gerados em público e privado, liberando-lhe reorientações às referências que foram empregadas no desenvolvimento de políticas públicas vítima com enfoque étnico.

Palavras chaves: Feminino, preto, deslocados, o conflito, a política pública.

\section{INTRODUCCIÓN}

El trabajo con mujeres negras desplazadas se emprendió a partir del problema de investigación centrado en el conflicto armado interno que hace de Colombia el segundo país con mayor desplazamiento forzado en 
el mundo, y en el cual, la población afrocolombiana es una de las principales afectadas junto a pueblos indígenas y campesinos. De esta población las mujeres negras son las más afectadas por el desplazamiento, particularmente padecen una especie de triple discriminación y victimización: como desplazadas, como negras y como mujeres.

En Colombia el desplazamiento ha llegado a catalogarse como un parámetro de identidad de la persona desplazada, pero contrario a esa idea, debe delimitarse y comprenderse como el fenómeno causado por un tercero a un individuo que genera un estado o circunstancia de tránsito o movilidad, en el cual se hace obligatorio el abandono del punto de inicio y arraigo, para dar paso a un ámbito de zozobra que no perfila un punto de llegada seguro, ni propio, ni deseado. El desplazamiento es el detonante del desarraigo y la vulnerabilidad en un contexto socio territorial determinado que acarrea la violación de un conjunto de derechos humanos categorizados en nuestro ordenamiento jurídico en distinta jerarquía, pero que ante todo, ha provocado profundas afectaciones en la dimensión pública y privada de quienes son víctimas del desplazamiento.

A las víctimas del conflicto en Colombia se sigue sumando que muchas mujeres de la población afrocolombiana ya no estén es sus territorios de origen, pasando a ubicarse en grandes ciudades como Medellín. En los lugares que las reciben, estas mujeres adquieren la calidad de desplazadas y víctimas; allí contaron sus historias, de las que el pueblo colombiano hace parte y de las cuales el mundo podrá comprender una fracción del conflicto que ha vivido este país.

Las preguntas que soportaron los ejercicios de investigación oral con las mujeres negras desplazadas fueron: ¿qué significa tener la piel negra en un país como Colombia?, ¿qué consecuencias trae que además ese cuerpo negro sea el de una mujer desplazada?, ¿cómo manifiesta el cuerpo tres victimizaciones?, ¿cómo impacta en lo privado ser víctima en tres sentidos?, ¿cómo han reconstruido sus vidas?, ¿cómo se resisten y recuperan?

La investigación propuso como objetivos explorar desde los testimonios de las mujeres negras las huellas y efectos dejados en ellas por el desplazamiento que las ha convertido en víctimas, y reconocer la violación de derechos y victimización que implica ese desplazamiento, haciendo pertinente y necesaria la indagación del referente normativo y sociocultural de política pública que viene siendo elaborado y ejecutado para hacer frente a esa situación que define como vulnerable a gran parte de la población afrocolombiana. 
Pero si bien esas mujeres negras son víctimas del desplazamiento forzado, cabe recordar que dicho fenómeno es secuela del conflicto armado desarrollado entre grupos al margen de la ley y el Estado, este último, garante de las medidas necesarias y pertinentes por medio de las cuales, con respaldo en el Estado de Derecho, debe proporcionar el amparo suficiente a una fracción inmersa en un conflicto del cual propiamente no son parte. De allí resultó fundamental describir y analizar el precedente jurídico que ha dado lugar a la implementación de una política pública nacional para la población en situación de desplazamiento en Colombia. Referente que ilustra el panorama en el cual se están desenvolviendo las vidas de las mujeres negras desplazadas.

Para acercarse a dicha realidad se acudió a una metodología cualitativa con un enfoque histórico hermenéutico, empleando el método documental, y a las estrategias de la historia oral a partir del testimonio. Como técnica se empleó la entrevista semiestructurada a mujeres negras desplazadas del departamento de Chocó en el occidente de Colombia, y de la región de Urabá, zona costera del departamento de Antioquia, las cuales se ubicaron después del desplazamiento en barrios periféricos de la comuna 13 y la comuna 8 de Medellín, siendo algunas de ellas víctimas de desplazamientos intraurbanos.

\section{REFERENTES DEL ORDENAMIENTO JURÍDICO}

La Constitución Política de Colombia en su artículo 2 consagra como fines esenciales del Estado "(...) servir a la comunidad, promover la prosperidad general y garantizar la efectividad de los principios, derechos y deberes consagrados en la Constitución (...)". Unido a estos fines la Carta Magna dispone:

(...) las autoridades de la República están instituidas para proteger a todas las personas residentes en Colombia, en su vida, honra, bienes, creencias y demás derechos y libertades, y para asegurar el cumplimiento de los deberes sociales del Estado y de los particulares (...) El Estado promoverá las condiciones para que la igualdad sea real y efectiva y adoptará medidas en favor de grupos discriminados o marginados (Constitución Política de Colombia, 1991, artículo 13).

La posibilidad de aplicación real de los derechos declarados de manera universal, como derechos adquiridos por la humanidad, es quizás el problema más grande que afrontan los Estados en desarrollo; más aún 
cuando se trata de reivindicaciones ancestrales con perspectiva étnica y de género: cultura, tierra, familia, comunidad, costumbres, todos ellos arrasados con un proceso violento como el desplazamiento forzado. Esta dificultad radica, precisamente, en que se intenta universalizar la realidad de pueblos particulares que no se ajustan a las representaciones occidentalizadas de ciudadano.

Desde la misma época de la Conquista deviene para la historia de Colombia el drama del desplazamiento coercitivo, cuando las víctimas fueron primero los indígenas a quienes se les arrebató su patrimonio y su cultura, siendo pocos los que lograron huir de esta primera arremetida; luego vino el largo período de la esclavitud de la población negra, dando lugar al negro (afro), conminado a escapar y a esconderse como cimarrón.

Pero adicional a esos antecedentes desde comienzos de los años sesenta se ha propagado por todo el territorio nacional el fenómeno de la violencia armada irregular (de izquierdas y derechas), por cuya desenfrenada e inatajable espiral se ha generado una tragedia humanitaria de tales proporciones y tan diversas consecuencias, que en nuestros tiempos ha ganado el poco honor de figurar en los registros internacionales en materia de desplazamiento forzado de personas, entre las naciones del mundo con más alto índice.

El conflicto armado interno en Colombia proporciona realidades muy desalentadoras en materia de desplazamiento forzado. En una aproximación a este fenómeno el Departamento Nacional de Planeación de Colombia (DPN) que toma como base la información de la Red de Solidaridad Social, reportó que entre 1995 y 2005 se desplazaron en el país 1.166.284 personas, destacando que en los últimos dos años de ese periodo se presentaron disminuciones en las cifras, alcanzando 219.315 casos en el 2003, y 145.995 en 2004 (Ibañez \& Moya, 2007).

El Internal Displacement Monitoring Centre dependiente del Consejo Noruego de Desplazados, reportó en el primer semestre del 2008 los niveles más altos de movilización con cifras entre 1593 a 3890 personas en el suroccidente de Arauca, el sur de Nariño, el sur de Córdoba y el occidente del Valle del Cauca; lo que contribuyó a los datos ofrecidos por la Agencia de la ONU para los refugiados, que en el 2010 informó de un total de desplazados internos en Colombia equivalente a 3, 5 millones de personas (ACNUR, 2010). 
El Observatorio de Derechos Humanos y Derecho Internacional Humanitario de la República de Colombia aseguró que entre los meses de enero a octubre de 2010 se presentaron por fecha de salida 108.472 casos de desplazamiento, y por fecha de declaración de esa condición 183.880; para el año 2011 por fecha de salida fueron 106.141 las personas, y 286.758 los casos declarados. Dentro de esta realidad la población negra se identifica como una de las principales víctimas debido a que tan solo en el año 2001, 37.000 de los 342.000 desplazados pertenecían a la población afrodescendiente (Observatorio de los Derechos Humanos de la Vicepresidencia de Colombia, 2011).

Debido a que la investigación se concentra en testimonios de mujeres negras desplazadas de Chocó y Antioquia, se exalta que desde el Observatorio de los Derechos Humanos de la Vicepresidencia de Colombia (2012) en el periodo de enero a septiembre de 2009 en el Chocó fueron 5.536 las personas desplazadas, y en los mismos meses del 2010, 1.817. En el caso de Antioquia el número de personas en el 2009 fue de 16.694, y 10.409 en el 2010.

Siendo la población negra una de las más afectadas por este fenómeno, el marco jurídico en nuestro país viene pretendiendo afrontar la problemática en ascenso desde una política pública que en principio sólo buscaba soluciones coyunturales e inmediatistas para los afectados; sin embargo, poco a poco la internacionalización ha conducido a las distintas naciones a procurar la adopción de protocolos de protección a la población civil que ha sido víctima de violaciones a los derechos humanos, y por tanto, nuevas medidas que propendan por el cumplimiento de dichos compromisos.

Las normas internacionales que establecen un marco normativo de los derechos para la protección de la población desplazada fueron expuestas con claridad por la Corte Constitucional en el Auto 005 de 2009 que avanza en el análisis del tratamiento diferencial que debe darse a su problemática.

Los compromisos internacionales del Estado colombiano en materia de Derecho Internacional de los Derechos Humanos y Derecho Internacional Humanitario, también obligan a las autoridades a adoptar un enfoque de prevención del desplazamiento forzado que sea lo suficientemente diferenciado y específico como para incidir sobre las causas de fondo de este fenómeno y su impacto desproporcionado sobre las comunidades afrodescendientes y sus miembros. 
(...) Así mismo, los miembros de las comunidades afrodescendientes quedan cobijadas bajo dos de los principios fundamentales del Derecho Internacional Humanitario, a saber, a) el principio de distinción -que prohíbe, entre otras cosas, dirigir ataques contra la población civil, la prohibición de utilizar métodos de combate o armas de efectos indiscriminados, y los actos destinados a sembrar terror entre la población civil, que usualmente preceden y causan el desplazamiento, y en otras oportunidades ocurren después de que el desplazamiento ha tenido lugar-, y b) el principio de trato humanitario - que cobija a los afrodescendientes, en tanto varias garantías fundamentales les son directamente aplicables a la situación de riesgo que padecen en virtud del conflicto armado interno ${ }^{1}$.

Uno de los principios rectores de los desplazamientos internos de las Naciones Unidas, los cuales se basan en disposiciones pertinentes del Derecho Internacional Humanitario y del Derecho Internacional de los Derechos Humanos, merece resaltarse en función de la protección de los miembros de las comunidades afrodescendientes, el Principio 4, según el cual: “1) Estos Principios se aplicarán sin distinción alguna de raza, color, sexo, idioma, religión o creencia, opinión política o de cualquier otra indole, origen nacional, étnico o social, condición jurídica o social, edad, discapacidad, posición económica, nacimiento o cualquier otro criterio similar"; el Principio $6^{\circ}$ que prohíbe los desplazamientos arbitrarios incluyendo aquellos "a) basados en politicas de apartheid, "limpieza étnica" o prácticas similares cuyo objeto o resultado sea la alteración de la composición étnica, religiosa o racial de la población afectada”; y el Principio 9, de conformidad con el cual "los Estados tienen la obligación específica de tomar medidas de protección contra los desplazamientos de pueblos indígenas, minorías, campesinos,

1 Entre ellas (i) la prohibición de la discriminación en la aplicación del Derecho Internacional Humanitario; (ii) la prohibición del homicidio; (iii) la prohibición de la tortura y de los tratos crueles, inhumanos y degradantes -que es en sí misma una norma de ius cogens-; (iv) la prohibición de los castigos corporales y los suplicios-norma de ius cogens como tal-; (v) la prohibición de las mutilaciones, de las experimentaciones médicas o científicas u otras actuaciones médicas no requeridas por la persona afectada y contrarias a las normas médicas generalmente aceptadas-la cual de por sí es una norma de ius cogens-; (vi) la prohibición de violencia sexual, de la prostitución forzada y de los atentados contra el pudor; (vii) la prohibición de la esclavitud y de la trata de esclavos-norma con rango propio de ius cogens-; (viii) la prohibición del trabajo forzado no retribuido o abusivo; (ix) la prohibición de las desapariciones forzadas; (x) la prohibición de la privación arbitraria de la libertad; (xi) la obligación de respetar las garantías judiciales esenciales y por los principios de legalidad de los delitos y de las penas y de responsabilidad penal individual; (xii) la prohibición de los castigos colectivos; (xiii) la prohibición absoluta de los crímenes de lesa humanidad cometidos en el curso de un conflicto armado -norma igualmente revestida del carácter autónomo de ius cogens-, y (xiv) la prohibición de los actos de terrorismo. 
pastores y otros grupos que experimentan una dependencia especial de su tierra o un apego particular a ella". (Corte Constitucional de Colombia, 2009, Auto 005).

Pero a la par de los pronunciamientos jurisprudenciales del máximo Tribunal constitucional, las mujeres negras desplazadas de esta zona del país deben ser un objeto de especial protección a la luz de importantes normas internacionales ratificadas por el Estado colombiano. La protección de los derechos de las víctimas y la perspectiva de género que debe caracterizar la eficacia de las normas que sirven de referente de la política pública, están enmarcados en el Sistema Interamericano de Protección de Derechos Humanos (SIDH) a través de la Convención Americana sobre Derechos Humanos, la Convención Interamericana para Prevenir, Sancionar y Erradicar la Violencia Contra la Mujer (Convención de Belem do Pará) y el Protocolo de San Salvador sobre Derechos Económicos, Sociales y Culturales los cuales, estando aprobados por el Estado, deben ser garantía de seguridad jurídica como integrantes del Bloque de Constitucionalidad.

Para la atención a víctimas de desplazamiento forzado en el ámbito nacional se ha desarrollado un cuerpo normativo con el que se ha buscado adoptar las disposiciones pertinentes para la atención y asistencia a la población en situación de desplazamiento. La ley que ha puesto en el escenario nacional a los desplazados es la 387 de 1997, por la cual se adoptan medidas para la prevención del desplazamiento forzado y la atención, protección, consolidación y estabilización socioeconómica de los desplazados internos por la violencia.

Siendo un factor adicional que en Colombia ahonda la marginalidad (ser negra, ser mujer, ser desplazada), el desplazamiento de quienes lo padecían no eran una "masa", sino un pueblo diferenciado en todo su tejido, en especial para las negritudes y desde la vivencia femenina; y a fuerza de decisiones de la Corte sobre la materia y que son antecedente al memorable Auto 005 de 2009, se estableció el plan de acción para la prevención y atención del desplazamiento forzado, producido por el Consejo de Política Económica y Social (CONPES) ${ }^{2}$ desde el 10 de noviembre de 1999. En él se dispone una "atención diferencial de la población desplazada", teniendo en cuenta los criterios de edad, género, discapacidad y procedencia étnica.

2 El Consejo Nacional de Política Económica y Social — Conpes — fue creado por la Ley 19 de 1958. Esta es la máxima autoridad nacional de planeación y se desempeña como organismo asesor del Gobierno en todos los aspectos relacionados con el desarrollo económico y social del país. Para lograrlo, coordina y orienta a los organismos encargados de la dirección económica y social en el Gobierno, a través del estudio y aprobación de documentos sobre el desarrollo de políticas generales que son presentados en sesión. Recuperado de https://www.dnp.gov.co/CONPES.aspx 
En lo concerniente al género se partía del reconocimiento de que cerca de la mitad de las familias desplazadas tienen mujeres como jefas de hogar. Por lo tanto se buscaba incentivar desde esa época los proyectos productivos y de generación de ingresos, facilidades de acceso a servicios de salud, educación y vivienda, así como atención preferencial por parte del Instituto Colombiano de Bienestar Familiar (ICBF) a los hijos e hijas de estas madres trabajadoras (Ramírez, 2001).

La perspectiva de género resulta fundamental para alcanzar los fines del Estado Social de Derecho, en garantía del principio de igualdad material, que según la Corte Constitucional es fundamental para guiar las tareas del Estado, que tienen como fin corregir las desigualdades existentes, promover la inclusión social, y lograr que los grupos sociales que se encuentren en situación de desigualdad tengan un goce efectivo de sus derechos (Corte Constitucional, 2001, C-106). La perspectiva de género permite tener visión de las relaciones de poder existentes entre hombres y mujeres, y desde ello da cuenta de algunos grupos sociales que se ven excluidos y en situación de desigualdad. Si bien el principal fin del Estado Social de Derecho es garantizar el goce de los derechos fundamentales de los asociados, la perspectiva de género debe permitir identificar desigualdades históricas que no permiten el goce de esos derechos.

La Corte visibiliza los efectos diferenciados y desproporcionados que el desplazamiento forzado tiene en la vida de las mujeres y reconoce especial vulnerabilidad de las desplazadas por la violencia y la violación grave y sistemática de sus derechos fundamentales, así como la ausencia de un enfoque diferencial sensible a sus necesidades específicas. Constata que la situación de las mujeres, jóvenes, niñas y adultas mayores desplazadas por el conflicto armado en Colombia constituye una de las manifestaciones más críticas del estado de cosas inconstitucional declarado en la sentencia T-025 de 2004, por ser sujetos de protección constitucional múltiple y reforzada, cuyos derechos están siendo vulnerados en forma sistemática, extendida y masiva a lo largo de todo el territorio nacional. Así se ejemplificaba en las voces de las mujeres negras:

La guerrilla perseguía mucho donde nosotros vivíamos, entonces ya uno (...) como allá se trabaja en el campo, en el monte, hay mucho miedo de ir al monte a trabajar porque uno no sabía qué le iba a salir, ya la guerrilla se mantenía en el monte, ya la gente mantenía en las casas y el que se queda en la casa se muere de hambre, entonces ya a uno le tocaba venirse de por allá. 


\section{$(\ldots)$}

Más de una vez pensé en devolverme, pero el Chocó ahora está peor que antes. Ahora hay más grupos armados allá, además en el pueblo abusan de las mujeres, y como ya tengo mis hijos y son jóvenes me da mucho miedo. Siempre ha existido eso, pero yo creo que ahora la gente es más como sin piedad (...) me tocaba ver abuso a las mujeres de los grupos armados, no alguien cercano, pero si gente conocida, entonces a uno lo obligan a huir, porque son cosas que al menos, a mí me da mucho miedo eso, ya habían hecho un poco de homicidios. Aunque volver, pues, bueno. ("Josefina", testimonio, 2011).

Pero, ¿qué tantos resultados se han logrado para la atención integral de la población desplazada y principalmente para contener la tragedia humanitaria que esta circunstancia representa para las víctimas en la última década? La respuesta podría estar en la atención que actualmente reciben mujeres como Josefina, afrocolombianas víctimas de esa clase de violencia, y de los resultados que en ellas se vivencia en materia de restitución de sus derechos: “¿Cómo te encuentras, Josefina, después de que te conminaron por la fuerza a desplazarte desde tu región hasta Medellín?: ¡Muy bien, hasta mercado me han dado!”

Esa franca exclamación de una de las mujeres entrevistadas denota un demérito del Estado cuando se aplican las políticas públicas, porque se asimila la idea de que las víctimas como la población afrocolombiana en situación de desplazamiento y despojo, no deben añorar sus orígenes culturales, su relación con la tierra, su música, su comunidad y sus costumbres ancestrales, como esos derechos principales que se deben recobrar.

Cuando yo vivía en Apartadó la idea de nosotras era el talento, porque nosotros íbamos, bailábamos, en ese entonces nos llevaban dizque a hacer comparsas. Cosas de niñas. Bailábamos en esos eventos y todo, ahora que yo me salí para Medellín, ya como que perdí la costumbre, ya no me gusta el baile, viví ya, viví como otra cultura diferente a la de Apartadó, porque allá era la música por toda parte y el baile y el ambiente y todas esas cosas, y yo llegué aquí a Medellín y me dediqué a trabajar. ("Roberta", testimonio, 2011).

Frente a una necesidad y un abandono tan profundo del que llega a tierras extrañas se induce un impulso mendicante que difunde esta "solución" 
desde el perfil de "cuánto me han ayudado", "cuánto más me deben dar" para no asumir la problemática de fondo (por lo menos fuera del papel), porque desgraciadamente esa es la sensación que se percibe del "gran esfuerzo estatal" al salir de una sede de Acción Social y de sus unidades de atención y orientación a la población desplazada (UAO).

El reconocimiento del carácter estructural de las dos realidades (exclusión y desplazamiento) y las interrelaciones entre ellas, exige que un enfoque diferencial étnico-afrocolombiano busque transformar las causas y factores estructurales implicados en ambas. En otras palabras, una política pública con enfoque diferencial étnico afrocolombiano que pretenda tener éxito para detener y prevenir el fenómeno del desplazamiento, debe transformar las condiciones de exclusión estructural en que sigue viviendo el pueblo afrocolombiano.

\section{DERECHO A LA VERDAD, LA JUSTICIA Y LA REPARACIÓN INTEGRAL EN EL MARCO DE LA JUSTICIA TRANSICIONAL}

A partir de 2005 entra a rondar en el contexto colombiano el concepto de justicia transicional ${ }^{3}$, con lo que se conoció como proceso de desmovilización de los grupos paramilitares. Se creó un marco normativo como escenario para la búsqueda, por la vía judicial, de la verdad, la justicia y la reparación para las víctimas; fue así como se expidió la Ley 975 de 2005. Los paramilitares arrepentidos tendrían la posibilidad de gozar de penas alternativas de hasta 8 años, incluso para delitos de lesa humanidad, develando sus crímenes y reparando el daño causado.

Para un proceso de paz y reconciliación nacional, este modo de justicia transicional fue aceptado en el ámbito internacional, pues persigue un bien superior para la sociedad, en especial para detener la espiral de violencia, garantizando que no se repetirán los actos de barbarie a los que se ha sometido a toda la población civil. Sin embargo, transcurridos más de 5 años después de su vigencia los verdaderos fines con los que se promovió esta ley por parte del Gobierno vigente para la época y los resultados que la misma ha arrojado, son materia de ardua polémica entre quienes la defienden a ultranza y tratan de implementarla desde la institucionalidad, realzando las estadísticas en materia de

3 La justicia transicional es una respuesta a las violaciones sistemáticas o generalizadas a los derechos humanos. Su objetivo es reconocer a las víctimas y promover iniciativas de paz, reconciliación y democracia. La justicia transicional no es una forma especial de justicia, sino una justicia adaptada a sociedades que se transforman a sí mismas después de un período de violación generalizada de los derechos humanos. En algunos casos, estas transformaciones suceden de un momento a otro; en otros, pueden tener lugar después de muchas décadas. Recuperado de http://www.ictj.org/es/tj/ 
exhumaciones, identificación de víctimas desaparecidas y esclarecimiento de crímenes atroces, y quienes esperaban mejores resultados, en especial para las víctimas en materia de verdad y reparación integral, la cual no se ha logrado si se compara con el volumen de hechos denunciados.

Este primer paso estuvo acompañado en 2008 del decreto 1290, mediante el cual se promovía la reparación, ya no en despachos judiciales, sino por vía administrativa. Con esta norma, el compendio de bienes jurídicos a reparar incluye hechos en el marco del conflicto armado colombiano que se remontan al año de 1964 teniendo como actores a los grupos guerrilleros y paramilitares, dejando por fuera los actos atribuibles a los agentes del Estado. En el mismo se establece una especie de "tarifa" del daño, ofreciendo a los damnificados por la violencia un máximo de 40 salarios mínimos legales mensuales vigentes (aproximadamente 8.500 Euros). A la fecha existen más de trescientos mil reclamantes y las estadísticas oficiales hablan de más de $30 \mathrm{mil}$ personas "reparadas".

Pero, siendo la población afro y en particular la mujer negra, de las más afectadas por el conflicto armado, ¿cómo se viene ocupando la justicia transicional de ellas?, ¿cómo se afronta el desplazamiento forzado en normas concebidas para el posconflicto?

Me desplazaron de la comuna. Usted sabe que el trabajo de uno líder es muy delicado (...) el problema del desplazamiento de la comuna fue porque yo tengo una asociación y yo trabajo para la comunidad y yo hacía mucha labor social y usted sabe que los paramilitares (...). El problema es que ahora sacaron la policía comunitaria que siempre ha existido, la policía llega a mi sede por lo que nosotros hacemos labor social y usted sabe que como esos barrios están calientes, ellos piensan que uno es sapo, que es un mensajero de la policía, no sé ellos qué se imaginan.

Yo tenía un programa muy bien montado en la comuna. Tenía varias actividades allí, nosotros hacíamos las escobas y las traperas, trabajábamos la parte del reciclaje. Entonces unas mujeres hacíamos escobas y traperas y las otras reciclábamos, entre el mismo programa de la asociación yo tenía un programa de 160 niños que les dábamos un vaso de leche, entonces movíamos mucha cositas con el municipio pensando en la comunidad. (...) ("Roberta", testimonio, 2011). 
Repasando la primera de las normas que hemos nombrado, tendríamos que decir que las palabras negra y desplazamiento no hacen parte del texto de la ley; sin embargo, las mismas han sido remplazadas por el género de víctimas ${ }^{4}$. En teoría la Ley 975 permite a las mujeres afro en situación de desplazamiento o que hayan sufrido otros actos de barbarie producto del conflicto armado, reclamar la reparación integral del daño sufrido, para que quien lo causó lo resarza, y en caso de que se compruebe su imposibilidad de hacerlo, sea el Estado de manera solidaria quien asuma parte del costo de la reparación(léase: indemnización).

Decimos en teoría porque el fenómeno de la violencia y el desplazamiento han afectado de tal manera al género femenino afro, adultas y niñas, que la llamada reparación integral en todo su contexto tendría que tener efectos no sólo individuales, sino especialmente colectivos, quedando en evidencia que el escenario ofrecido por este proceso judicial estará inmerso en un sinnúmero de hipótesis ideales de reparación pedidas por las víctimas ante los magistrados de conocimiento, pero con poco respaldo en lo que puede ofrecer la propia decisión judicial.

Gran parte de la problemática que ha surgido con la violación masiva de sus derechos, como al territorio, la vida en comunidad, el desarrollo de sus costumbres ancestrales, y a la identidad cultural, deben ser asumidas por políticas públicas como lo ha propuesto en su análisis la Corte Constitucional. Es muy probable, como se vislumbra ya en los primeros fallos, que se sacrifiquen criterios de restitución plena de derechos, en un esfuerzo judicial por proveer algo de verdad y de justicia.

En esencia, no existe en Colombia, aún, la capacidad de proveer reparación integral a partir de un fallo judicial en un proceso penal como el que establece la justicia transicional, a consecuencia del gran volumen

4 CONGRESO DE LA REPUBLICA. LEY 975 DE 2005. Artículo 5. Definición de víctima. Para los efectos de la presente ley se entiende por víctima la persona que individual o colectivamente haya sufrido daños directos tales como lesiones transitorias o permanentes que ocasionen algún tipo de discapacidad física, psíquica y/o sensorial (visual y/o auditiva), sufrimiento emocional, pérdida financiera o menoscabo de sus derechos fundamentales. Los daños deberán ser consecuencia de acciones que hayan transgredido la legislación penal, realizadas por grupos armados organizados al margen de la ley. También se tendrá por víctima al cónyuge, compañero o compañera permanente, y familiar en primer grado de consanguinidad, primero civil de la víctima directa, cuando a esta se le hubiere dado muerte o estuviere desaparecida. La condición de víctima se adquiere con independencia de que se identifique, aprehenda procese o condene al autor de la conducta punible y sin consideración a la relación familiar existente entre el autor y la víctima. Igualmente se considerarán como víctimas a los miembros de la Fuerza Pública que hayan sufrido lesiones transitorias o permanentes que ocasionen algún tipo de discapacidad física, psíquica y/o sensorial (visual o auditiva), o menoscabo de sus derechos fundamentales, como consecuencia de las acciones de algún integrante o miembros de los grupos armados organizados al margen de la ley. Asimismo, se tendrán como víctimas al cónyuge, compañero o compañera permanente y familiares en primer grado de consanguinidad, de los miembros de la fuerza pública que hayan perdido la vida en desarrollo de actos del servicio, en relación con el mismo, o fuera de él, como consecuencia de los actos ejecutados por algún integrante o miembros de los grupos organizados al margen de la ley. En: Diario Oficial No. 45.980. Bogotá: Imprenta Nacional, 2005. 
de hechos denunciados y a la acumulación histórica de impunidad frente a la precaria capacidad de la rama judicial, pero puede aproximarse a algunos de los aspectos que esta clase de reparación exige, como la verdad colectiva que requieren las comunidades afrodescendientes sobre las causas del despojo y el destierro sufrido en las últimas décadas. La dinámica del conflicto y del posconflicto tienen relevancia para la vigencia temporal que contempla esta ley, por cuanto fija un límite, agosto de 2005, para la ejecución de hechos violentos que puedan ser reparados. Es decir, nuevamente en teoría, el conflicto armado colombiano cesó el 25 de julio de 2005, lo cual por supuesto es irreal.

Por su parte el decreto 1290 de 2008 efectúa definiciones teóricas de lo que son los derechos, sin que la norma tenga clara tendencia en materia de diferenciación para tratar los temas étnicos o de género. Para desplazamiento forzado tasa el derecho de reparación administrativa en 27 salarios mínimos legales mensuales vigentes, pero redimibles a través de los programas de vivienda por "núcleo familiar". Lo anterior sin perjuicio de poder acceder a los demás conceptos de reparación que contempla el mismo decreto en caso de que el daño provenga de otros asuntos distintos al desplazamiento como el secuestro, los homicidios, la tortura, la violencia sexual, entre otros.

De esa forma se comienzan a desarrollar los conceptos de restitución ${ }^{5}$, rehabilitación ${ }^{6}$, medidas de satisfacción ${ }^{7}$ y garantías de no repetición de

5 Artículo $6^{\circ}$. Restitución. El Comité de Reparaciones Administrativas dispondrá, cuando ello fuere posible, las acciones que permitan a la víctima regresar a la situación anterior a la comisión del delito. Parágrafo. Las medidas consistentes en restitución de tierras se regirán por las normas aplicables a esa materia.

6 Artículo $7^{\circ}$. Rehabilitación. El Estado, a través de este programa, prestará a las víctimas que lo requieran asistencia para su recuperación de traumas físicos y psicológicos sufridos como consecuencia del tipo de victimización de que trata este decreto.

7 Artículo $8^{\circ}$. Medidas de satisfacción. Sin perjuicio de lo previsto por el parágrafo $1^{\circ}$ del artículo $4^{\circ}$ del presente decreto, el Comité de Reparaciones Administrativas adoptará alguna o algunas de las siguientes medidas de satisfacción en beneficio de las víctimas o beneficiarios:

a) Reconocimiento público del carácter de víctima, de su dignidad, nombre y honor, ante la comunidad y el ofensor; b) Efectuar las publicaciones a que haya lugar relacionadas con el literal anterior, a través de la Agencia Presidencial para la Acción Social y la Cooperación Internacional-Acción Social; c) Realización de actos conmemorativos, a través de la Agencia Presidencial para la Acción Social y la Cooperación Internacional-Acción Social; d) Otorgamiento de condecoraciones y otros reconocimientos públicos, a través de la Agencia Presidencial para la Acción Social y la Cooperación Internacional-Acción Social; e) Realización de homenajes públicos, a través de la Agencia Presidencial para la Acción Social y la Cooperación Internacional-Acción Social; f) Construcción de monumentos públicos en perspectiva de reparación y reconciliación, a través de la Agencia Presidencial para la Acción Social y la Cooperación Internacional-Acción Social; g) Difusión pública y completa del relato de las víctimas sobre el hecho que las victimizó, siempre que no provoque más daños innecesarios ni genere peligros de seguridad, a través de la Agencia Presidencial para la Acción Social y la Cooperación Internacional-Acción Social; h) Colaborar para la identificación de cadáveres y su inhumación posterior, según las tradiciones familiares y comunitarias, a través de las entidades competentes para tal fin; i) Acceso preferente a los servicios sociales ofrecidos por el Estado, a través de las diferentes entidades y organismos competentes, j) Difusión de las disculpas y aceptaciones de responsabilidad hechas por los victimarios, a través de la Agencia Presidencial para la Acción Social y la Cooperación Internacional-Acción Social. Parágrafo. Para la aplicación de las medidas de satisfacción a que se refieren los literales anteriores, se deberá contar con el consentimiento de las víctimas. 
las conductas delictivas ${ }^{8}$, aunque la misma norma no crea los instrumentos necesarios para que pueda darse la reivindicación de los mismos a quienes los reclaman. Incluso, remite nuevamente a los medios judiciales la posibilidad de exigir el compendio de asuntos que no alcanza a amparar esta norma ${ }^{9}$. El decreto en realidad no crea instrumentos para dar alcance real a los derechos que promulga; más bien se ocupa de definir una indemnización que sustituya la reparación para los casos más graves que genera la violencia armada.

En la primera etapa de aplicación del decreto 1290 de 2008 se ha cumplido, en parte, aunque de manera desordenada con las primeras indemnizaciones económicas, aunque se empeñan los medios oficiales en llamarlas "primeras reparaciones". Pero para la comunidad negra queda pendiente en materia transicional la reparación de fondo. Para corroborar lo anterior baste repasar el concepto de restitución que se expuso anteriormente, el cual, no es asumido por este decreto: "El reconocimiento del carácter estructural de las dos realidades (exclusión y desplazamiento) y las interrelaciones entre ellas, exige que un enfoque diferencial étnico-afrocolombiano busque transformar las causas y factores estructurales implicados en ambas."

En el año 2011 se debatió y aprobó en el Congreso de la República una nueva Ley de Víctimas (1448 de 2011) que aspira a ser un avance en todos los temas teórico prácticos que han producido en los últimos años sus antecesoras. Contrario a la anterior legislación, aún vigente, las palabras mujer, negra, afrocolombianos, raizales y palenqueras sí hacen parte del texto. El denominado enfoque diferencial empieza a tener mayor espacio en este nuevo sendero en la búsqueda de la justicia restaurativa con esta población ${ }^{10}$. Pero quizás el mayor avance esté en la intención de integrar a todos los órganos del Estado alrededor de la exploración de la satisfacción plena de los derechos de las víctimas; es por lo menos la intención de hacer efectivo el principio constitucional de colaboración armónica para atender la crisis humanitaria de las víctimas.

8 Artículo $9^{\circ}$. Garantías de no repetición de las conductas delictivas. El Gobierno Nacional pondrá en ejecución acciones encaminadas a prevenir que las conductas violatorias a los derechos fundamentales se repitan. Igualmente, se adelantarán campañas de capacitación, difusión y promoción para la observancia de las normas nacionales e internacionales sobre derechos fundamentales.

9 Artículo 11. Derechos no incluidos. El reconocimiento de las medidas de reparación a las que se refiere el presente programa, no excluye aquellas que solo fuere posible tramitar por la vía judicial, de modo que la víctima podrá acudir para estos efectos ante la autoridad judicial respectiva.

10 Artículo 13. Enfoque diferencial. El principio de enfoque diferencial reconoce que hay poblaciones con características particulares en razón de su edad, género, orientación sexual y situación de discapacidad. Por tal razón, las medidas de ayuda humanitaria, atención, asistencia y reparación integral que se establecen en la presente ley, contarán con dicho enfoque. 
En el compendio de principios de la nueva ley, se encuentra el de colaboración integral en el que se establece que todas las entidades del Estado deberán trabajar de manera armónica y articulada para el cumplimiento de los fines previstos en la Ley (artículo 26) y el de la asistencia y atención (artículo 49) en el que se entiende por asistencia a las víctimas: el conjunto integrado de medidas, programas y recursos de orden político, económico, social, fiscal, entre otros, a cargo del Estado, orientado a restablecer la vigencia efectiva de los derechos de las víctimas, brindarles condiciones para llevar una vida digna y garantizar su incorporación a la vida social, económica y política.

Tratándose de la población afro no puede aspirarse a menos si lo que se busca es atacar a fondo las causas que hoy la mantienen en la marginalidad. Siendo un asunto de gran complejidad, extiende esta nueva ley la posibilidad de crear o mejorar la normatividad vigente relacionada con la población indígena, y afrocolombiana, grupos étnicos que serán consultados a fin de respetar sus usos y costumbres.

Es así como el artículo 205 de la ley 1448 establece lo que será la suerte final de estas comunidades, otorgando facultades extraordinarias al Presidente de la República por el término de seis meses, contados a partir de la expedición de la ley, para regular, por medio de decretos, los derechos y garantías de las víctimas pertenecientes a pueblos y comunidades indígenas, ROM y negras, afrocolombianas, raizales y palenqueras en lo relativo al marco legal de la política pública de atención, reparación integral y de restitución de tierras, que desarrollen la política pública diferencial para las víctimas pertenecientes a estos pueblos y comunidades.

Dentro de los principales aspectos que contribuyen al reconocimiento público de las víctimas y sus derechos, la ley recientemente aprobada contempla la inclusión de los campesinos dentro del listado de grupos reconocidos como más vulnerables, de forma tal que el Estado ofrecerá mayores garantías y medidas de protección. Contempla disposiciones específicas en materia de género, en tanto observa que vivir libres de violencia es un derecho autónomo y exigible por parte de las mujeres. Consagra como deber de la Defensoría del Pueblo el incorporar criterios de asesoría diferenciales y un componente de asistencia para las mujeres víctimas en todas sus actuaciones como representante judicial.

La nueva ley amplía medidas legales previas en materia de salud y educación que beneficiarán a las víctimas, entre las que se encuentran 
la exención de cualquier cobro de copago a aquellas que se encuentren cubiertas por el plan subsidiado de salud, la posibilidad de que se exima de cobros por servicios académicos incluso en instituciones de carácter privado, la inclusión en los servicios de salud del examen de VIH y de ETS, para los casos en que la víctima haya sido objeto de violación o violencia sexual. Uno de los propósitos fundamentales de la ley es la creación de un marco de justicia transicional civil que supere las barreras de acceso presentes en la legislación ordinaria, así como la puesta en marcha de un sistema de información unificado de predios despojados, que contribuya a la restitución de bienes inmuebles rurales.

En lo referente a las comunidades étnicas, se establecen disposiciones para que ellas puedan hacer efectivo el derecho fundamental a la consulta previa. Finalmente en lo que atañe a la mujer, el tratamiento de esta ley avanza en el enfoque de género, sin hacer distinción étnica, especialmente en materia de restitución de tierras. Teniendo en cuenta el alto índice de incidencia del despojo en estas comunidades, resulta interesante que se otorguen algunas concesiones diferenciales en la atención para las mujeres en los trámites administrativos y judiciales del proceso de restitución.

Por lo menos en lo que refleja su contenido, esta ley es una oportunidad histórica para atacar a profundidad las causas del no trato diferencial a estas comunidades, siempre y cuando se respete el mecanismo de la consulta previa y la concertación, desarrollada en los largos períodos de avance jurisprudencial de la Corte Constitucional, aplicando los principios internacionales que reconocen las características especiales de la población afrocolombiana. En las relaciones de las mujeres negras víctimas con las instituciones y programas de atención del Estado, ellas viven sentimientos contradictorios. Son generalizados los de indignación, humillación, aunque también en ocasiones hay gratitud por "las ayudas" recibidas.

El primer paso de la víctima en el proceso para recibir atención por parte del Estado es lograr ser reconocida por este como persona en situación de desplazamiento, es decir, tener el estatus de "desplazado". Antes de ello, habrá tenido que superar el temor a hacer la solicitud para ser reconocida como víctima de desplazamiento; temor que se genera debido a la estigmatización por parte de las instituciones y de la sociedad, y sobre todo, a la persecución de los actores armados. 
Las mujeres se lamentan de la pérdida de su autonomía económica, del tener que pasar a depender de las ayudas del Estado o peor aún el tener que llegar a pedir dinero en las calles. Ellas se la "rebuscan", entran a hacer parte de la creciente población de Medellín que vive de trabajos informales, con las desventajas adicionales de su escasa educación, desconocimiento del medio, pocas oportunidades laborales y discriminación. En Medellín estas mujeres víctimas se han ido encontrando y reconociendo como tales, lo que ha significado la oportunidad de organizarse colectivamente para reclamar sus derechos como víctimas.

Pero las víctimas están siendo asesinadas. A través de sus testimonios las mujeres negras denuncian públicamente el asesinato de sus hijos, sus esposos y familiares, la amenaza bajo la que están permanentemente, la triple discriminación que padecen día a día de parte de todos los actores armados ilegales, pero también de algunas instituciones y miembros del Estado. Piden y exigen justicia, que cese la impunidad, que se restablezcan sus derechos, así como reparación y protección para las víctimas. Piden que se detenga la violencia y nos convocan a todos a romper el miedo, la indiferencia, a dejar de creer que "a mí no me hacen nada porque yo no me meto en nada" o que cuando asesinan a alguien "por algo será, algo habrá hecho".

Para los afros esta violencia atenta contra su fortalecimiento y continuidad cultural, pues sus territorios ancestrales son también referentes, ejes de su cultura y garantía de esta, son sus pequeñas patrias, a las que, aunque se trabaje y viva en otros lugares del país, siempre se retorna a sus fiestas, se acude en vacaciones o en cualquier otra oportunidad para compartir con sus familias, parientes, paisanos, reforzando con ello vínculos de sentimiento y arraigo. La violencia en sus territorios rompe estos lazos, afecta estas articulaciones de los afros ubicados en Medellín con las raíces en sus tierras de origen como Chocó, Urabá, y otras regiones importantes de nucleación y raíces de la población afrocolombiana.

Para muchos afros el proceso de desplazamiento ha sido de las veredas o caseríos al municipio, y de este a ciudades capitales: Quibdó, Barranquilla, Cartagena, Cali, ciudades con fuerte presencia afro y a ciudades del interior, como Medellín y Bogotá, donde también hay importantes asentamientos afro. Pero otra gran parte de ellos siguen resistiendo en sus territorios, presionados por los actores armados al confinamiento y bajo la presión, también, de los inversionistas y del 
mismo Estado para quienes estos territorios son estratégicos dentro de sus planes de modernización y enriquecimiento.

Las mujeres negras desplazadas sufren hoy un inmenso dolor, por lo que requieren y tienen derecho a una atención especial. Atención psicológica que les ayude a superar estas pérdidas, hacer sus duelos, superar el dolor y el miedo, reconstruir su autoestima. En lo que se refiere al tratamiento de las secuelas emocionales y psicológicas presentes en las víctimas del conflicto armado en Colombia, el Sistema General de Seguridad Social en Salud (SGSSS), considera la atención psicológica como un asunto accesorio y del cual sólo pueden beneficiarse las personas que tienen un riesgo emocional grave.

En caso de que una persona en situación de desplazamiento cuente con cobertura en salud bajo el régimen subsidiado, es responsabilidad de la EPSS $^{11}$ financiar los servicios del POSS ${ }^{12}$, y si no está afiliada al SGSSS, la atención que pudiese llegar a necesitar deberá ser financiada por la entidad territorial del lugar en que reside con cargo a los recursos del $\mathrm{SGP}^{13}$. Según dispone el Acuerdo 306 de 2005 del Ministerio de la Protección Social, el POSS excluye la atención especializada en salud mental y los servicios de mediana y alta complejidad de las afecciones mentales, aunque sí contempla acciones en promoción, prevención y en recuperación de la salud en servicios de baja complejidad, así como los necesarios en cualquier complejidad para la rehabilitación funcional. Lo anterior, en la práctica, quiere decir:

(...) el POSS cubre el manejo ambulatorio y con internación, por parte del médico general y por enfermería no especializada de patologías mentales no complicadas o que no requieren atención de servicios de mediana y alta complejidad ni consulta por médico especialista o por sicología. (Corte Constitucional de Colombia, 2010, sentencia T - 045).

Para el caso del régimen contributivo la atención en salud física y mental también está restringida en la medida que los procedimientos del $\operatorname{POS}^{14}$ impiden la atención terapéutica a mediano y largo plazo (Corte Constitucional de Colombia, 2010, sentencia T - 045). La atención en salud mental dentro del POS, es considerada como una especie de "cenicienta" (Arboleda, 2007) en tanto no se corresponde con las

11 Empresa Promotora de Salud del Régimen Subsidiado, anteriormente conocida como Administradora del Régimen Subsidiado(ARS)

12 Plan Obligatorio de Salud del Régimen Subsidiado.

13 Sistema General de Participaciones.

14 Plan Obligatorio de Salud del régimen contributivo 
necesidades de la población y mucho menos con las patologías mentales que requieren seguimiento y evaluación por largo tiempo.

Esta se restringe fundamentalmente al tratamiento farmacológico, y aun así, es bastante desactualizada. Se observa que lo psíquico está medicalizado, expresado en términos dicotómicos de enfermedad sanidad, y por ese camino la comprensión de lo psicológico se dificulta sobremanera. Es así que la psicoterapia se encuentra excluida en la práctica, a menos que el interesado cuente con un plan complementario de salud. La Ley 100 de 1993 contempla la atención psicológica sólo en casos "problemáticos" y es considerada como una especialidad médica, dejando de lado el componente preventivo. Con ello se considera que en este campo no hay urgencias, reduciéndose la posibilidad de encontrar atención profesional en salud mental.

De tal magnitud es la falta de atención en este campo que, en palabras de la Defensoría del Pueblo, esta es proporcionada por organizaciones no gubernamentales y fundaciones "remplazando la responsabilidad de las instituciones estatales que, por misión, deben desarrollar programas de atención especializada de la población vulnerable por los efectos del conflicto armado interno" (Corte Constitucional de Colombia, 2010, sentencia T - 045).

Siguiendo este orden de ideas puede colegirse que las políticas públicas en salud mental son, en la práctica, insuficientes, no existen programas que evidencien que la atención psicosocial es de vital importancia para la salud de los colombianos en general y de los que han sido víctimas del conflicto armado en particular. La Procuraduría General de la Nación (2009: 11) reconoce que el Estado colombiano, a través de las distintas entidades y programas encargados de atender a la población en situación de desplazamiento, a los familiares de personas desaparecidas y asesinadas, y a los miles de menores víctimas de reclutamiento forzado, no ha brindado servicios de atención psicosocial de manera efectiva.

La Comisión Nacional de Reparación y Reconciliación (CNRR) asegura que en Antioquia, la población afectada por la violencia carece de una atención adecuada de las secuelas psicológicas asociadas a los eventos traumáticos sufridos. Del mismo modo, se considera problemático el abandono psicosocial que han padecido y continúan padeciendo las víctimas de la violencia, hecho que supone en gran medida una revictimización, y justifica la atención en aquellos casos que presenten graves secuelas y en aquellos susceptibles de presentarlas. 
El último estudio nacional (Ministerio de la Protección Social, 2005) en dicha materia señala que 4 de cada 10 colombianos han sufrido en algún momento de su vida un problema o trastorno mental. Para el caso del grupo poblacional denominado como víctimas del conflicto armado no existen datos sobre incidencia o prevalencia de trastornos mentales, y el mencionado estudio no brinda señales al respecto. Por ejemplo las palabras "desplazado/a, desplazamiento" no aparecen siquiera mencionadas, y la consideración que sobre la violencia urbana y el conflicto armado se hace es en términos de que "la salud mental y los trastornos mentales están relacionados con el ambiente y con (dichos) procesos sociales tan complejos (...)" (Ministerio de la Protección Social, 2005).

"Relacionados" no parece congraciarse con el impacto en la vida, la salud mental, la capacidad de trabajar, ni vincularse con sus congéneres que se han manifestado en alrededor de 4.000 .000 personas en situación de desplazamiento registradas por Acción Social. "Relacionados" no es una palabra que impulse la formulación de políticas públicas que brinden el soporte para lograr una atención oportuna y efectiva en salud mental para las múltiples secuelas de guerra y violencia generalizada que ha sufrido el país en su historia reciente. "Relacionados" parece que aún no hace alusión al grupo afrodescendiente de Colombia como una víctima con profundas afectaciones y vulnerabilidad de forma integral e inmediata.

\section{CONCLUSIONES}

Luego de las barbaries y el sufrimiento, Colombia levanta miradas a distintos sectores de la población para identificarse y reconocerse en las víctimas como parte de la vivencia de un proceso crudo que ha segregado a distintos sectores sociales a situaciones de vulneración profunda. Entre ellos las mujeres negras cargan una de las más memorables y palpables herencias de la historia colonial africana que levantó los cimientos de gran parte de Latinoamérica, y son ahora, ejemplo de los atentados de una violencia generalizada fruto de un extendido conflicto armado interno.

Del conflicto interno han resultado severas presiones institucionales nacionales e internacionales sobre el Estado colombiano, actor de la confrontación, gestor de primer orden para una posible salida del mismo, y obligado directo en la elaboración y debida ejecución de políticas públicas dirigida a los diversos sectores que sufren las secuelas concomitantes producidas por el conflicto. A la presión de las distintas 
autoridades Colombia ha dado respuesta con un naciente proceso de normatización jurídica que proporciona el marco y la seguridad para el diseño y ejecución de políticas precisas dirigidas a la población desplazada de manera forzosa por los distintos grupos armados al margen de la ley, sin que el Estado aún se asuma y reconozca como un promotor más de atentados contra los Derechos Humanos y el Derecho Internacional Humanitario.

Las normas para los procesos de justicia transicional dieron lugar a una primera experiencia en la cual la ineficacia de la verdad, justicia y reparación, generó la modificación del marco legislativo a un proceso de restitución de tierras esperanzador en el cual ahora se leen, si bien aún de manera secular, los grupos étnicos como los afrodescendientes, los cuales antes eran invisibles para los creadores y ejecutores de la ley, integrados a una masa común e indistinta con la cual se desconocían sus características particulares como el poder ancestral del territorio, la colectividad de la propiedad y la identidad cultural.

El soporte jurídico está ahora definido por la Ley 1448 de 2011, que detalla y perfecciona las posibilidades institucionales para hacer frente a la crisis humanitaria de la población afrocolombiana. Adicionalmente se referencia una intervención profunda y garantista del activismo judicial de la Corte Constitucional, que ahonda la urgencia en la implementación de políticas públicas por parte de las autoridades administrativas.

Muchas de las medidas requeridas son ahora disposiciones jurídicas destinadas a efectivizar las condiciones de desplazados como las mujeres negras, como una de las formas de reparación, contrarrestando la exclusión y el desplazamiento, y encaminando las medidas de garantía de la restitución, rehabilitación y satisfacción de necesidades, en este caso con una perspectiva diferencial de fundamento étnico afrocolombiano que debe ser definido por el poder público. Medidas en educación, vivienda y acceso a la justicia se suman a las promovidas en el área de la salud, donde se exalta que la atención psicosocial a las víctimas del conflicto armado no puede contemplar solamente el cuidado psicológico y psiquiátrico, bastante escaso por lo demás. Si la implementación de estrategias en pro de la salud mental no hace parte de ninguna política pública, más preocupante aún es el hecho de que se hable de políticas estatales de equidad y género que no se compadecen con la situación que han vivido miles de hombres y mujeres en Colombia a raíz del conflicto armado. 


\section{REFERENCIAS BIBLIOGRÁFICAS}

Arboleda, J. C. (2007, septiembre). Salud mental: La "cenicienta" del POS. El Pulso. Periódico para el sector de la salud. Recuperado de: http://www.periodicoelpulso.com/html/0709sep/debate/debate10.htm

Centro Internacional para la Justicia Transicional \& Agencia Sueca para la Cooperación Internacional para el Desarrollo. (2009). Valoración de los programas oficiales de atención psicosocial a las víctimas del conflicto armado interno en Colombia. Bogotá, Colombia: Procuraduría General de la Nación.

Colombia. Congreso de la República. Ley 387 de 1997. "Por la cual se adoptan medidas para la prevención del desplazamiento forzado; la atención, protección, consolidación y esta estabilización socioeconómica de los desplazados internos por la violencia en la República de Colombia”. En: Diario Oficial: No. 43.091. Bogotá: Imprenta Nacional, 1997.

Colombia. Corte Constitucional. Sentencia del 22 de enero de 2004. Magistrado Ponente: Manuel José Cepeda Espinosa. (Sentencia Número $\mathrm{T}-025)$

Colombia. Corte Constitucional. Auto del 4 de mayo de 2007. Magistrado Ponente: Manuel José Cepeda E. (Auto Número 109)

Colombia. Corte Constitucional. Auto de 7 de septiembre de 2007. Magistrado Ponente: Manuel José Cepeda E. (Auto Número 233)

Corte Constitucional de Colombia. Auto de 13 de mayo de 2008. Magistrado Ponente: Manuel José Cepeda E. (Auto Número 116)

Colombia. Corte Constitucional. Sentencia del 10 de febrero de 2004. Magistrada Ponente: Clara Inés Vargas Hernández. (Sentencia Número C $-106)$

Colombia. Corte Constitucional. Auto de 26 de enero de 2009. Magistrado Ponente: Manuel José Cepeda Espinosa. (Auto Número 005)

Colombia. Presidencia de la República. Decreto 1290 de 2008. "Por el cual se crea el Programa de Reparación Individual por vía Administrativa 
para las Víctimas de los Grupos Armados Organizados al Margen de la ley”. En: Diario Oficial: No 46968. Bogotá: Imprenta Nacional, 2008.

Ibañez.A. M. \& Moya. A. (2007). La población desplazada en Colombia: Examen de sus condiciones socioeconómicas y análisis de las políticas actuales. Bogotá: Departamento Nacional de Planeación de Colombia.

Internal Displacement Monitoring Centre. (2008). Recuperado de: http:// www.internal-displacement.org/8025708F004BE3B1/(httpInfoFiles)/ 093BEDA 2D1625DDCC12574E3004828C3/\$file/col_ocha_idps_1 jan-30jun08.gif

Ministerio de Justicia y del Derecho de Colombia. (2012). Ley de víctimas y restitución de tierras. Recuperado de: http://www.ley devictimas.gov.co/\#!_ quien-es-victima

Ministerio de la Protección Social. (2005). Estudio Nacional de Salud Mental Colombia 2003. Bogotá, Colombia: Fundación FES-SOCIAL.

Observatorio de Derechos Humanos y Derecho Internacional Humanitario de la Presidencia de la República de Colombia. (2012). Recuperado de: http://www.derechoshumanos.gov.co/Observatorio/ Paginas/Observatorio.aspx

Ramírez, M. H. (2001). El impacto del desplazamiento forzado sobre las mujeres en Colombia. En: Amérique Latine Histoire y Mémoire. Recuperado de: http://alhim.revues.org/index531.html\#tocto1n4 